\title{
Moeten toezichthouders wakker liggen van de Meavita-uitspraak van de Ondernemingskamer?
}

Ageeth Klaassen

\section{Inleiding}

Het Meavita-concern ontstond op 1 januari 2007 door een bestuurlijke fusie van de Meavitagroep en Sensire\&Thuiszorg Groningen (S\&TZG). Het concern hield zich bezig met de verlening van zorg en thuiszorg op grond van de Algemene Wet Bijzondere Ziekenkosten (AWBZ). Dit werd later, vanaf 2007, de Wet maatschappelijke ondersteuning (Wmo). Na het faillissement van het Meavita-concern in 2009 heeft Abvakabo FNV in 2010 een verzoek ingediend om een enquêteprocedure te starten. De Ondernemingskamer van het Gerechtshof Amsterdam (OK) heeft in november 2015 wanbeleid bij het Meavita-concern ${ }^{1}$ vastgesteld, met name ten aanzien van de fusie tussen de Meavitagroep en S\&TZG en het besluit om te investeren in het TVfoon-project. Voor dat wanbeleid zijn de bestuurders respectievelijk de leden van de toezichthoudende organen van het Meavita-concern verantwoordelijk. ${ }^{2}$ De originele beschikking van de OK is 191 pagina's. In het hiernavolgende beperk ik mij daarom tot de betekenis van deze uitspraak voor (intern) toezichthouders ${ }^{3}$ vanuit juridisch perspectief.

\section{Wanbeleid is nog geen aansprakelijkheid}

De Meavita-uitspraak is een beschikking van de OK in het kader van een enquêteprocedure. Een enquêteprocedure bestaat uit twee afzonderlijke fasen. In de eerste fase beziet de OK of er gegronde redenen zijn om aan een juist beleid te twijfelen. Als dat het geval is, kan de OK onderzoekers benoemen. Dat is bij Meavita gebeurd. In de tweede fase beziet de OK of uit het onderzoeksverslag van wanbeleid is gebleken. Daarvan was bij Meavita sprake. In dat geval kan de OK voorzieningen treffen. Ook kan de OK de verantwoordelijkheden voor dat wanbeleid in de kosten van het onderzoek veroordelen. Hieruit blijkt een belangrijk doel van het enquêterecht, te weten het bieden van opening van zaken en vaststellen wie verantwoordelijk is voor mogelijk wanbeleid. Een enquêteprocedure heeft daarmee een ander doel dan een procedure om aansprakelijkheid van (bestuurders en) toezichthouders vast te stellen voor de geleden schade. Het gaat om twee afzonderlijke procedures. Vandaar dat FNV op 9 februari 2016 bekendmaakte de verantwoordelijke (bestuurders en) toezichthouders in een afzonderlijke procedure

1 Het ging om Meavitagroep en S\&TZG/Meavita Nederland.

2 Hof Amsterdam (OK) 2 november 2015, ECLI:NL:GHAMS:2015:4454.

3 Ik hanteer steeds de term toezichthouders, toezichthoudend orgaan of raad van toezicht (RvT). Binnen het Meavita-concern werden de toezichthoudende organen aangeduid met RvT of raad van commissarissen $(\operatorname{Rv} C)$. 
financieel aansprakelijk te stellen voor de schade die is ontstaan door hun wanbeleid. ${ }^{4}$ Deze aansprakelijkheidsprocedure wordt aanhangig gemaakt bij de rechtbank.

In de praktijk wordt het wanbeleidoordeel van de OK in een enquêteprocedure als opstap voor een aansprakelijkheidsprocedure tegen (bestuurders of) leden van de RvT gebruikt. Vaststelling van wanbeleid impliceert geen persoonlijke aansprakelijkheid van deze leden. Het oordeel van de OK dat van wanbeleid sprake is geweest kan in de aansprakelijkheidsprocedure enige bewijsrechtelijke betekenis hebben. ${ }^{5}$ Tegen de beschikking van de OK hebben de (bestuurders en) toezichthouders cassatie bij de Hoge Raad ingesteld. ${ }^{6}$ Afwachten is dus of en in hoeverre de Hoge Raad het wanbeleidoordeel van de OK in stand laat. In voetbaltermen gesproken: op dit moment staan de (bestuurders en) toezichthouders van Meavita na de eerste helft met 1-0 achter, maar de tweede helft moet nog gespeeld worden.

\section{Uitspraak}

Zoals gezegd, voor het vastgestelde wanbeleid zijn de leden van de toezichthoudende organen van het Meavita-concern verantwoordelijk. In de kern komt het op het volgende neer: ${ }^{7}$

1. De leden van de RvT zijn, naast het bestuur, verantwoordelijk voor de voorbereiding en uitvoering van een fusie. Het fusiedocument bevatte slechts dertien pagina's. Het is onvoldoende als de doelstellingen van de fusie op hoofdlijnen worden vastgesteld. Een duidelijke taakstelling van het bestuur mag volgens de OK niet ontbreken en er moeten afspraken worden gemaakt over de wijze en de tijdstippen waarop de RvT toezicht houdt op de verwezenlijking van de doelstellingen. In het fusiedocument mag ook een financiële en risicoparagraaf niet ontbreken. Hier kan niet van worden afgezien omdat de toekomst nog onzeker is. Juist daarom zijn deze paragrafen zeer gewenst, aldus de OK.

2. De RvT is verantwoordelijk voor de samenstelling van het bestuur. Er was volgens de OK onvoldoende financiële deskundigheid in het bestuur. De omstandigheid dat de markt van financiële expertise in de zorg krap was en het daardoor moeilijk was om - tegen het beoogde salaris, te weten maximaal de Balkenendenorm - een geschikte kandidaat te vinden, vormt hiervoor in de ogen van de OK onvoldoende rechtvaardiging.

3. De RvT is verantwoordelijk voor de profielschetsen bij zowel de benoeming van bestuurders als toezichthouders. De discussie ging over de - beperkte - keuze tus-

4 Zie <www.fnv.nl/sector-en-cao/alle-sectoren/zorg-en-welzijn/vvt/nieuws/1154107/> en Skipr Daily 4 januari 2016 (FNV wil Meavita-top aansprakelijk stellen voor schade werknemers).

5 HR 8 april 2006, NJ 2006/443 en JOR 2005/119 (Laurus).

6 Zie Skipr Daily 9 februari 2016 (Meavita-top vecht uitspraak wanbeleid aan). De datum boven de uitspraak zou bijvoorbeeld niet kloppen <www.skipr.nl>.

$7 \quad$ Volgens de OK levert het handelen en nalaten op de punten 1 en 3-7 afzonderlijk wanbeleid op. Punt 2 heeft bijgedragen aan het oordeel van wanbeleid. Zie C. de Groot, Wanbeleid bij Meavita?, MvO 2016/2 over de vraag of het oordeel dat sprake is van wanbeleid in alle opzichten terecht is. 
sen de in de fusiepartners zittende bestuursvoorzitters in plaats van dat er sprake was van een zakelijke voorbereiding door het opstellen van objectieve criteria, vastgelegd in profielschetsen. Dit vergrootte volgens de $\mathrm{OK}$ het risico dat bij de te maken keuzes niet de geschiktheid voor de te vervullen functies maar andere factoren (een 'eerlijke verdeling' en een uitruil van functies en dergelijke) de overhand kregen. Dit ernstige risico heeft de RvT ook genomen door voor zijn eigen samenstelling geen profielen op te stellen. Dit klemt volgens de OK temeer omdat dit laatste in artikel 4.2.8 ZGC staat.

4. De leden van de RvT zijn verantwoordelijk voor het houden van functionerings- en beoordelingsgesprekken van bestuurders. De OK verwijst naar artikel 4.1.4 ZGC, waarin staat dat deze gesprekken jaarlijks gevoerd moeten worden. Door niet eerder een functionerings- en beoordelingsgesprek te houden hebben de toezichthouders zich de mogelijkheid ontnomen een oordeel te vormen over ontslag of maatregelen ter versterking of uitbreiding van het bestuur, aldus de OK.

5. De RvT is verantwoordelijk voor de informatievoorziening binnen de RvT. In het bijzonder is een taak weggelegd voor de voorzitter, maar dat ontheft de andere leden niet van hun plicht. De OK verwijst hierbij naar principe III.4 en best practice bepaling III.4.1 sub b van de Nederlandse corporate governance code, de code voor beursgenoteerde vennootschappen. Deze bepalingen gaan specifiek over de rol van de voorzitter, waarover in de Zorgbrede Governancecode niets staat. ${ }^{8}$ In de ogen van de OK mogen medetoezichthouders belangrijke signalen over het functioneren van een bestuurder niet worden onthouden. De vrees voor oppositie en/of aftreden van leden van de RvT vormden daarvoor geen rechtvaardiging. Bovendien waren de nieuwe RvT-leden bij hun benoeming niet voldoende op de hoogte gesteld 'van het zware weer waarin de organisatie verkeerde'. Dat sommige ontwikkelingen zich in de vakantie voordeden of kort voor het aantreden van de nieuwe leden, doet niet ter zake. De voorzitter van de RvT is niet 'een vader die zijn kinderen voor bestaande of komende gevaren moet beschermen', aldus de OK. ${ }^{9}$

6. De RvT is verantwoordelijk voor het toezicht op omvangrijke projecten. Volgens de OK had de RvT bij meer aandacht voor het project Vita Plaza eerder de gebreken van het project kunnen signaleren en had hij eerder kunnen ingrijpen.

7. De RvT is verantwoordelijk voor het toezicht op de naleving van de medezeggenschapsregels. Volgens de OK heeft de RvT na het ontdekken van het overtreden van de Wet op de ondernemingsraden en de Wet medezeggenschap cliënten zorginstellingen daaraan geen consequenties verbonden. De OK noemt het zelfs onbegrijpelijk dat de RvT hiermee heeft ingestemd. ${ }^{10}$

8 Alleen in art. 3.1.5 ZGC wordt gesproken over de voorzitter van de RvT. Vermeende onregelmatigheden die het functioneren van leden van de Raad van Bestuur betreffen, worden gerapporteerd aan de voorzitter van de RvT.

9 R.o. 6.41.

10 Zie voor andere uitspraken over de rol van de RvT en medezeggenschap: Hof Amsterdam (OK) 29 april 2010, JOR 2010/187 (Zorgcentra De Betuwe); Hof Amsterdam (OK) 20 mei 2010, JOR 2010/188, m.nt. L.G. Verburg (Sherpa); Hof Amsterdam (OK) 19 april 2013, JOR 2013/206, m.nt. R.C. de Mol (Stichting Ilmarinen). 


\section{Beschouwing}

Wat is de betekenis van deze uitspraak voor leden van de RvT vanuit juridisch perspectief? Dit is de eerste uitspraak, voor zover mij bekend, waarin de OK daadwerkelijk wanbeleid heeft vastgesteld bij een zorgstichting. ${ }^{11}$ Dit komt omdat nog niet eerder een dergelijk verzoek om wanbeleid vast te stellen is gedaan. De Meavita-uitspraak is niet de eerste beschikking waarin het toezichthoudend orgaan medeverantwoordelijk wordt gehouden voor wanbeleid. Voorbeelden van andere OK-uitspraken zijn bijvoorbeeld OGEM, Textlite en Laurus. ${ }^{12}$ In deze uitspraken ging het om (beursgenoteerde) vennootschappen.

Uit de Meavita-beschikking blijkt mijns inziens dat de taakopvatting van een RvT in een zorgstichting niet wezenlijk verschilt met die van de $\mathrm{RvC}$ van een (beursgenoteerde) vennootschap. Er zal steeds toezicht moeten worden gehouden. ${ }^{13}$ Daaraan worden bepaalde eisen gesteld. Gezien de professionaliseringslag die het toezicht en de toezichthouders in de zorgsector hebben gemaakt, zal de maatschappelijke invloed van de opvatting van de OK niet al te groot zijn. Opmerkelijk kan wellicht zijn dat de woorden 'publiek belang' nergens in de uitspraak worden genoemd. ${ }^{14}$ Uit deze uitspraak blijkt niet dat toezichthouders in de zorg een zwaardere taak hebben. ${ }^{15} \mathrm{Zij}$ opereren alleen in een ander veld. ${ }^{16}$

Bij gebrek aan wettelijke regels verwijst de OK, voor zover het gaat om de verantwoordelijkheden van de RvT, alleen naar bepalingen uit de Zorgbrede Governancecode en één keer naar bepalingen uit de Nederlandse corporate governance

11 Twee keer heeft de OK een verzoek toegewezen, maar het is niet gekomen tot een oordeel over een eventueel wanbeleid, zie Hof Amsterdam (OK) 29 april 2010, JOR 2010/187 (Zorgcentra De Betuwe); Hof Amsterdam (OK) 20 mei 2010, JOR 2010/188, m.nt. L.G. Verburg (Sherpa). Twee keer is een verzoek afgewezen, zie Hof Amsterdam (OK) 19 april 2013, JOR 2013/206, m.nt. R.C. de Mol (Stichting Ilmarinen) en Hof Amsterdam (OK) 29 oktober 2014, ARO 2014/183 (Zuwe Hofpoort Ziekenhuis). Bij het Slotervaartziekenhuis kwam de OK tot het oordeel dat er geen sprake was van wanbeleid, maar in deze casus ging het om bv's, zie Hof Amsterdam (OK) 13 mei 2015, ARO 2015/146.

12 HR 10 januari 1990, NJ 1990/466 (OGEM); HR 4 juni 1997, NJ 1997/671 (Textlite); Hof Amsterdam (OK) 16 oktober 2003, JOR 2003/260, m.nt. Brink (Laurus).

13 Voor een (beursgenoteerde) nv volgt dit uit art. 2:140 BW en voor een zorgstichting uit art. 6.1 UBWTZI en art. 4.1.1 ZGC. Wanneer het Voorontwerp Wet bestuur en toezicht rechtspersonen tot wet wordt verheven, komt dit voor stichtingen te staan in art. 2:292a lid 2 BW (nieuw): 'Het toezichthoudend orgaan heeft tot taak toezicht te houden op het beleid van het bestuur en op de algemene gang van zaken in de stichting en de met haar verbonden organisatie.' <www. internetconsultatie.nl/bestuurentoezichtrechtspersonen>.

14 Zie hierover het advies van de Commissie Behoorlijk bestuur (commissie-Halsema), Een lastig gesprek, september 2013.

15 Vgl. r.o. 6.19. Hieruit zou wellicht geconcludeerd kunnen worden dat een fusie in de zorgsector meer aandacht behoeft dan een fusie in het bedrijfsleven.

16 De bijzonder moeilijke periode waarin de toezichthouders moesten opereren, zoals de invoering van de WMO, concurrentie, onbetaalde overproductie tegenover zorgplicht, overeenkomsten met tientallen gemeenten (via aanbesteding) enz. Deze en andere omstandigheden kunnen mogelijk een verklaring vormen voor minder gunstige ontwikkelingen in of slechte resultaten van een onderneming. Zij kunnen echter geen rechtvaardiging vormen voor de vastgestelde tekortkomingen, aldus de OK. Zie hierover r.o. 13.19. 
code. De stichtingsbepalingen in Boek 2 BW kennen geen artikelen over de RvT. ${ }^{17}$ Ook in sectorale zorgwetgeving is de positie van de RvT beperkt geregeld, namelijk in één artikel, artikel 6.1 Uitvoeringsbesluit WTZi. De verwijzingen naar de Zorgbrede Governancecode door de OK om de taak van de (leden van de) RvT te duiden zijn dan ook niet opmerkelijk, mede gezien de betekenis die de OK en de Hoge Raad in eerdere uitspraken hebben gegeven aan de Nederlandse corporate governance code. ${ }^{18}$ Deze code vormt een uiting van de in Nederland heersende algemene rechtsovertuiging.

De vraag is alleen wel of dit ook geldt voor de Zorgbrede Governancecode. Deze is niet wettelijk verankerd, zoals de Nederlandse corporate governance code dat wel is. ${ }^{19}$ Voor zorginstellingen die lid zijn van de Brancheorganisaties Zorg (BoZ) geldt de toepassing van de Zorgbrede Governancecode als lidmaatschapsverplichting. In hoeverre speelt dat een rol? De vraag is ook of het een rol speelt dat Meavita zelf de Zorgbrede Governancecode heeft aanvaard en later haar eigen code, met de Zorgbrede Governancecode overeenstemmend, toepaste. De OK heeft geen aandacht besteed aan deze punten en lijkt de Zorgbrede Governancecode op een lijn te zetten met de Nederlandse corporate governance code. Mijn vermoeden is dat er cassatieklachten zullen zijn over de toepassing van de Zorgbrede Governancecode. De Hoge Raad zal dan dus duidelijkheid moeten geven over de (juridische) status van de Zorgbrede Governancecode. ${ }^{20} \mathrm{Om}$ in voetbaltermen te blijven, de Hoge Raad zal moeten oordelen of de OK terecht met de Zorgbrede Governancecode een rode kaart heeft gegeven.

Van (maatschappelijk) belang is dat de Zorgbrede Governancecode, net zoals de Nederlandse corporate governance code, ${ }^{21}$ up-to-date blijft. De bepalingen in de Zorgbrede Governancecode, die stamt uit 2005, zijn in 2010, na de ondergang van het Meavita-concern, uitgebreid en worden volgens de Brancheorganisaties

17 Met uitzondering van art. 2:300 BW. De bevoegdheid tot vaststelling tot de jaarrekening komt aan het toezichthoudend orgaan toe, indien aanwezig.

18 HR 21 februari 2003, NJ 2003/182 (HBG), HR 13 juli 2007, NJ 2007/434 (ABN AMRO), HR 14 september 2007, NJ 2007/612 (Versatel), HR 9 juli 2010, NJ 2010/544 (ASMI). Overigens merkt de OK een aantal keren op dat de bepalingen in de ZGC en de Meavitacode niet van doorslaggevende betekenis zijn geweest. Met andere woorden: het oordeel van de OK was niet anders geweest als de normen niet waren vastgelegd. Zie r.o. 6.25 en 6.30.

19 Zie art. 2:391 lid 5 BW voor de NCGC en de Regeling Verslaggeving WTZi (RVWTZi) voor de ZGC. In art. 8a van deze regeling staat dat de jaarverslaggeving en het jaardocument worden opgesteld met gebruikmaking van een modeljaardocument. Dit modeljaardocument is te vinden op de website <www.jaarverslagenzorg.nl>. In dit jaardocument, onderdeel B.1., dient de zorginstelling antwoord te geven op de volgende vragen: 'Hanteert uw concern de ZGC? Zo nee, welke andere code? Nee, omdat...'. In de toelichting op B.1. staat dat het voor de hand ligt om de ZGC te hanteren. Zie Jaarverantwoording zorginstellingen 2016, onderdeel B.1, p. 48 en onderdeel F.2.1., p. 86. De RVWTZi is op dit punt gewijzigd. De vraag is dus ook nog of er verschil is tussen het nu geldende recht en het destijds geldende recht.

20 Andere vragen zullen zijn of het schenden van een bepaalde bepaling uit de ZGC wanbeleid kan opleveren en of de OK reflexwerking mag toekennen aan de NCGC voor (zorg)stichtingen. Zie voor dat laatste: De Groot 2016/2.

21 Momenteel ligt een herziene versie ter consultatie voor, zie <www.commissiecorporategovern ance.nl>. 
Zorg (BoZ) binnenkort 'herijkt en stevig vernieuwd'. ${ }^{22}$ Wellicht kan de rol van de voorzitter van de RvT bij de herziening van Zorgbrede Governancecode worden opgepakt. ${ }^{23}$ Maatschappelijk wordt de Zorgbrede Governancecode al breed gedragen is mijn indruk.

Afgezien van de negatieve publiciteit kan de meeste betekenis van de OK-beschikking worden gehecht aan de kostenveroordeling van de toezichthouders. De OK heeft het verzoek tot kostenverhaal van de onderzoekskosten op de toezichthouders toegewezen. Dit komt bijna nooit voor. De leden van de toezichthoudende organen moeten 40 procent van de onderzoekskosten dragen, oftewel 400.000 euro. ${ }^{24}$ Dit is een vorm van aansprakelijkheid. ${ }^{25}$ RvT-leden zullen dit zeker zo ervaren. Zoals ik hiervoor opmerkte, volgt de echte aansprakelijkheidsprocedure voor de geleden schade nog.

De Meavita-casus is voor de wetgever reden geweest om actie te ondernemen, zo blijkt uit een brief van de staatssecretaris van Volksgezondheid, Welzijn en Sport (VWS). ${ }^{26}$ Het aantal uit te oefenen nevenfuncties is sinds 1 januari 2013 voor toezichthouders (en bestuurders) gelimiteerd. ${ }^{27}$ Sinds 1 januari 2014 is de zorgspecifieke fusietoets ingevoerd. Onderdeel van dat wetsvoorstel is dat de $\mathrm{RvC}$ een concentratie $^{28}$ dient goed te keuren. ${ }^{29}$

Daarnaast zijn er ook nog andere maatregelen genomen of zijn deze aangekondigd. De bezoldiging van de leden van de RvT is verhoogd naar 10 procent, en voor voorzitters naar 15 procent van de voor de rechtspersoon geldende maxi-

22 Zie <www.brancheorganisatieszorg.nl/>, Nieuwsbericht van 3 december 2015 (Meer openbaarheid over declaraties in de zorg).

23 Overigens bevat de huidige ZGC ook geen bepaling over de informatievoorziening binnen de RvT en vereist de huidige ZGC ook geen profielschets voor een bestuurder.

24 Het onderzoeksbudget was eerst bepaald op 500.000 euro, maar in 2013 is dit bedrag verhoogd naar een miljoen euro. Hof Amsterdam (OK) 28 juni 2012, JOR 2012/320, m.nt. R.P. Jager.

25 W.J. Slagter \& B.F. Assink, Compendium van het ondernemingsrecht, Deventer: Kluwer 2013, p. 1803.

26 Zie voor het volledige overzicht, Kamerstukken II 2015/16, 32012, nr. 34.

27 Zie art. 2:297a en 2:297b BW. Het aantal nevenfuncties van de voorzitter van de RvT van Meavita was zelfs reden voor een Tweede Kamerlid om een motie in te dienen. Kamerstukken II 2008/09, 27295, nr. 144 (motie van het lid Agema). Volgens deze motie had de voorzitter dertig bijbanen.

28 Het begrip concentratie omvat niet alleen fusies, maar ook overnames en andere vormen van zeggenschapsoverdracht tussen zorgaanbieders zoals bestuurlijke of financiële deelnames. Kamerstukken II 2011/12, 33253, nr. 3, p. 32.

29 Art. 40 lid 1 onderdeel e, onder $2^{\circ}$ Wcz luidt: 'Het goedkeuren van een concentratie als omschreven in de Mededingingswet waarbij de zorgaanbieder is betrokken.' Onduidelijk is alleen of dit art. 40 Wcz (nieuw) al per 1 januari 2014 geldt, aangezien de Wcz nog niet is ingevoerd. Het betreft vermoedelijk een misslag. Bij een andere wet zijn de artikelen uit de Wcz uitgezonderd van invoering, hoewel daarvoor ook een Klein Koninklijk Besluit nodig was, aangezien men dit in eerste instantie over het hoofd had gezien. Zie Klein Koninklijk Besluit, Stb. 2013, 592. Zie hierover A.G.H. Klaassen, Van sprinkhanen en cowboys: bevoegdheden van de AVA en publieke belangen in de zorgsector, in: B.F. Assink, K.F. Haak, J.M. de Jongh, M.J. Kroeze \& A.J.P. Schild (red.), De toekomst van het ondernemingsrecht, Uitgave vanwege het Instituut voor Ondernemingsrecht, deel 99, Deventer: Wolters Kluwer 2015, par. 16.5.4. 
male bezoldiging (voor bestuurders). ${ }^{30}$ Van de minister van Veiligheid \& Justitie is nog de Wet bestuur en toezicht rechtspersonen te verwachten, waarin de positie van het toezichthoudend orgaan voor de stichting en een 'bestuursverbod' voor leden van de RvT van stichtingen worden geregeld. ${ }^{31}$ In plaats van een geschiktheidstoets, zoals gebruikelijk in de financiële sector, komt er een accreditatietraject voor toezichthouders. ${ }^{32}$ De minister van VWS wil graag dat een dergelijk traject een plaats krijgt in de ZGC. ${ }^{33}$ Ook wil VWS graag dat er in de ZGC een vergewisplicht komt voor de RvT bij benoeming van bestuurders. ${ }^{34}$ Bovendien wil VWS de naleving van de ZGC verbeteren. ${ }^{35}$ VWS ziet een door de sector zelf georganiseerde onafhankelijke monitoring op de naleving van de ZGC als een reële optie als aanvulling op het bestaande toezicht van de Inspectie voor de Gezondheidszorg (IGZ). ${ }^{36}$

Bij Meavita blijkt dat de RvT vooral op procedurele aspecten tekort is geschoten. Het lijkt mij dan ook dat deze OK-beschikking geen (directe) aanleiding geeft, mede gezien de maatregelen die al zijn ingevoerd of zullen worden ingevoerd, tot nieuwe maatregelen. ${ }^{37}$ Vaststaat al dat lid zijn van een RvT een vak is en geen erebaan. Dit wordt alleen maar bevestigd door de OK-beschikking, maar dat besef moeten toezichthouders al lang hebben, gezien de maatschappelijke discussie van de afgelopen jaren.

\section{Slot}

Kort gezegd is de les van de OK voor leden van de RvT: doe uw (toezicht)werk en leef de ZGC na. Hierbij moet in het achterhoofd worden gehouden dat de betekenis van de OK-beschikking vanuit juridisch oogpunt momenteel (nog) niet al te groot is. Eerst moeten we wachten of de Hoge Raad de uitspraak in stand laat en daarnaast is het afwachten of de toezichthouders daadwerkelijk voor het gevoerde beleid aansprakelijk worden gehouden in een aansprakelijkheidsprocedure. Voorlopig kunnen toezichthouders nog rustig slapen.

30 Zie art. 2.2 lid 1 WNT. Uit de jaarverslagen van Meavita blijkt dat Hermans in 200610.000 euro ontving en in 200715.000 euro. Zie Skipr Daily 4 juni 2014 (Toezichthouder Hermans werd slapend rijk).

31 Zie voor het voorontwerp, <www.internetconsultatie.nl/bestuurentoezichtrechtspersonen>. Zie voor het 'bestuursverbod', art. 2:298 lid 5 BW (nieuw). Doel van het wetsvoorstel is de kwaliteit van bestuur en toezicht bij stichtingen te verbeteren.

32 Kamerstukken II 2014/15, 32012, nr. 23, p. 4. VWS was toch al geen voorstander van een geschiktheidstoets. Zie Kamerstukken II 2013/14, 32012, nr. 15, p. 7. Zie hierover A.G.H. Klaassen, Bestuurderstoets voor de zorg (of niet)?, TvGR 2014, p. 642 e.v. Overigens blijkt niet uit de Meavita-beschikking dat de toezichthouders onvoldoende deskundig werden geacht.

33 Zie hierover A.G.H. Klaassen, Geen separaat wetsvoorstel Goed bestuur in de zorg, Ondernemingsrecht 2015/124.

34 Kamerstukken II 2014/15, 32012, nr. 23, p. 4.

35 Kamerstukken II 2014/15, 32012, nr. 23, p. 5.

36 Kamerstukken II 2014/15, 32012, nr. 24, p. 23.

37 Wellicht zal de Zorgbrede Governancecode worden aangepast, zie noot 23. 